OPEN ACCESS

Edited by: Xinghui Wang,

Fuzhou University, China

Reviewed by:

Chao Lai,

Jiangsu Normal University, China Yongqi Zhang,

University of Electronic Science and

Technology of China, China

*Correspondence:

Ming Song

mings@xzit.edu.cn

Specialty section:

This article was submitted to Electrochemical Energy Conversion and Storage,

a section of the journal Frontiers in Energy Research

Received: 30 September 2020 Accepted: 22 October 2020

Published: 12 November 2020

Citation:

Song M, Tan H, Tian L, Li J, XuY, Shi L,

Sun L, Zhuang $W$ and Du $X(2020)$ NiFeRu Layered Double Hydroxide and Its Derivatives Supported on Graphite

Foam as Binder-Free Cathode for

Nonaqueous $\mathrm{Li}_{-} \mathrm{O}_{2}$ Batteries.

Front. Energy Res. 8:612093.

doi: 10.3389/fenrg.2020.612093

\section{NiFeRu Layered Double Hydroxide and Its Derivatives Supported on Graphite Foam as Binder-Free Cathode for Nonaqueous $\mathrm{Li}-\mathrm{O}_{2}$ Batteries}

\author{
Ming Song ${ }^{1 *}$, Hua $\operatorname{Tan}^{2}$, Lin Tian ${ }^{1}$, Jing $L i^{1}$, Yan $X u^{1}$, Liluo Shi ${ }^{1}$, Limei Sun ${ }^{1}$, \\ Wenchang Zhuang ${ }^{1}$ and Xihua $\mathrm{Du}^{1}$ \\ ${ }^{1}$ College Materials and Chemical Engineering, Xuzhou University of Technology, Xuzhou, China, ${ }^{2}$ School of Physical and \\ Mathematical Sciences, Nanyang Technological University, Singapore, Singapore
}

$\mathrm{Li}-\mathrm{O}_{2}$ batteries (LOBs) generally referred as Li-air batteries (LABs) potentially have a high specific capacity among all kinds of metal-ion batteries. However, it suffers severely from sluggish discharge/charge kinetics. A binder-free integrated cathode is fabricated which contains NiFeRu layered double hydroxide (NiFeRu LDH) nanosheets grown on a 3D conductive graphite foam (NiFeRu LDH@GF) in this work. This integrated 3D cathode exhibits a specific capacity of $3,085 \mathrm{mAh} \mathrm{g}^{-1}$ and a cycle life of 46 . The electrochemical performances of NiFeRu LDH derived metal oxides (DMO@GF) by calcining NiFeRu LDH@GF at $350^{\circ} \mathrm{C}, 450^{\circ} \mathrm{C}$, and $550^{\circ} \mathrm{C}$ are also been investigated. The $450^{\circ} \mathrm{C}$ obtained DMO@GF (450DMO@GF) exhibits the highest catalytic activity for oxygen reduction/evolution reaction. The unique floccule-like and cross-connected structure of the 450-DMO@GF and its low charge transfer resistance are responsible for the outstanding electrochemical performance.

Keywords: $\mathrm{Li}-\mathrm{O}_{2}$ battery, layered double hydroxide, binder-free cathode, graphite foam, derived metal oxide

\section{INTRODUCTION}

The modern e-society has put increasing demand for new energy sources that can enable long-lasting power and fast charging and/or release of the energy. Among various available batteries, $\mathrm{Li}^{-} \mathrm{O}_{2}$ batteries (LOBs), which are also called Li-air batteries (LABs), have the highest theoretical specific energy of 3,505 $\mathrm{Wh} \mathrm{kg}^{-1}$. This specific energy is $\sim 10$ times that of Li-ion batteries (Bruce et al., 2012) and higher than other Li metal batteries (Xue et al., 2019; Sun et al., 2020). Therefore, LOBs have attracted immense interest since 1996 as the "holy grail" of batteries (Abraham and Jiang, 1996). However, the development of LOBs are slow because of their low energy efficiency caused by decomposition of nonaqueous electrolyte and carbon-based cathode (Freunberger et al., 2011; Ottakam Thotiyl et al., 2013), short cycle life caused by nonrecovery of the reaction surface/interface (Lu et al., 2016), and poor power performance led by low kinetics of electron $/ \mathrm{Li}^{+} / \mathrm{O}_{2}$ transport during the oxygen evolution reaction (OER) and oxygen reduction reaction (ORR) (Liu et al., 2015). These issues are all related to the properties of cathode materials, and achieving cathode with high electrochemical performances is still a big challenge. During the discharging process, $\mathrm{O}_{2}$ should be first reduced at the gas/liquid/solid $\left(\mathrm{O}_{2} / \mathrm{Li}^{+} / \mathrm{e}^{-}\right)$three-phase reaction interface of cathode. Then, the reduced $\mathrm{O}_{2}^{-}$will combine with $\mathrm{Li}^{+}$to form $\mathrm{Li}_{2} \mathrm{O}_{2}$. In the charging process, $\mathrm{Li}_{2} \mathrm{O}_{2}$ should be decomposed to $\mathrm{O}_{2}$ and $\mathrm{Li}^{+}$, which guarantees reuse of the reaction interface of cathode during the following cycles. In addition to the $\mathrm{Li}$ anode and electrolyte, these two discharging/charging 
processes are dependent on the catalytic activity of cathode for ORR and OER. The slow kinetics of ORR and OER taking place in the cathode will undoubtedly give rise to poor battery performances. Thus, there is consensus that a stable cathode material with high ORR and OER activity is the key player of LOBs.

To realize a stable cathode and a superior $\mathrm{Li}-\mathrm{O}_{2}$ battery, numerous research efforts concerning catalyst design and catalytic mechanism have been devoted to the electro-catalytic materials field (Chang et al., 2017). Various cathode materials based on carbon materials (Qin et al., 2019), heteroatom doping carbon material (Jiang et al., 2019), noble metal (Zhang et al., 2019), and metal oxides (Yuan et al., 2019) have been used to the LOBs. The aim is to enhance the performances of LOBs by promoting the reaction kinetics associated with $\mathrm{Li}_{2} \mathrm{O}_{2}$ generation/decomposition. In particular, the larger overpotential during the charging process than discharging process reveals more sluggish OER kinetics (Lyu et al., 2017). Layered double hydroxide (LDH) has become the protagonist in different areas including photochemistry (Zhao et al., 2014), adsorption ( $\mathrm{Gu}$ et al., 2015), drug delivery (Ribeiro et al., 2014), and water electrolysis due to its advantages such as more exposed catalytic active sites than $0 \mathrm{D}$ or $1 \mathrm{D}$ materials, large surface-to-bulk ratios, and easily controllable layered structure adjustment (Cai et al., 2019). Especially, LDHs have attracted increased attention because of their OER catalytic activity since 2013 (Gong et al., 2013). This implies that LDHs are promising in accelerating the kinetics during the charging process for LOBs. However, there are only limited research so far on LDH cathode of LOBs. Recently, cathodes of nonaqueous LOBs based on CoNiFe $\mathrm{LDH}$ and conductive $\mathrm{RuO}_{2.1}$ super-lattice composites have been fabricated by casting these composites with polyvinylidene fluoride (PVDF) binder on stainless steel mesh (Lu et al., 2020). It is worth mentioning that LDHs usually have poor conductivity and insufficient active edge sites. Therefore, binder-free cathodes with LDHs supported on conductive substrate will be more superior.

Herein, in this work, we design and realize an integrated binder-free cathode for LOBs by directly growing $\mathrm{LDH}$ on a graphite foam (LDH@GF). NiFe LDH doped by $\mathrm{Ru}$ (NiFeRu $\mathrm{LDH}$ ) is selected since catalysts based on trimetal usually offer higher catalytic activity for OER in comparison with bimetalcentered LDH, and Ru has high adsorption capabilities toward oxygen-containing intermediates (Seh et al., 2017). In addition, their derived metal oxides (DMOs) supported on the GF (DMO@ $\mathrm{GF}$ ), by calcination under different temperatures, are also investigated as cathodes of LOBs since transitional metal oxides (e.g., $\mathrm{NiO}$ (Tong et al., 2015)) and spinel oxides (e.g., $\mathrm{NiCo}_{2} \mathrm{O}_{4}$ (Sun et al., 2014)) have exhibited catalytic activity in LOBs.

\section{EXPERIMENT SECTION}

\section{Preparation of Cathode Materials}

The 3D graphite foam (GF) substrate was prepared by using the chemical vapor deposition (CVD) method using the nickel foam as a template according to our previous work (Chao et al., 2014; Song et al., 2020). After etching the nickel template using a solution of $1 \mathrm{M} \mathrm{FeCl}$ and $0.5 \mathrm{M} \mathrm{HCl}$, a free-standing GF $\left(\sim 0.5 \mathrm{mg} \mathrm{cm}^{-2}\right)$ was obtained. Then, a piece of $\mathrm{GF}$ was immersed into a mixed solution of $98 \% \mathrm{HNO}_{3}$ and $70 \%$ $\mathrm{H}_{2} \mathrm{SO}_{4}$ with a mole ratio of $1: 3$. After washing with deionized water, this hydrophilic-treated GF was immersed into ethylene glycol for $1 \mathrm{~h}$ and then transferred into a teflon autoclave containing a mixed solution of $\mathrm{Ni}(\mathrm{NO} 3) 2 \cdot 6 \mathrm{H} 2 \mathrm{O} / \mathrm{Fe}(\mathrm{NO} 3)$ $2 \cdot 9 \mathrm{H} 2 \mathrm{O} / \mathrm{RuCl} 3 / \mathrm{NH}_{4} \mathrm{~F} /$ urea (mole ratio is 5:4:1:35:35). The hydrothermal reaction was carried out at $120^{\circ} \mathrm{C}$ for $12 \mathrm{~h}$. Then, the NiFeRu LDH supported on GF (NiFeRu LDH@GF, $\sim 1.3 \mathrm{mg} \mathrm{cm}^{-2}$ ) cathode was obtained after cooling naturally and washing with deionized water. The fabrication process for NiFeRu LDH@GF cathode is shown in Figure 1.

The DMOs supported on the GF (DMO@GF, $\sim 1.0 \mathrm{mg} \mathrm{cm}^{-2}$ ) cathode was achieved through heating NiFeRu LDH@GF in a quartz tube furnace under $\operatorname{Ar}$ gas at $350^{\circ} \mathrm{C}, 450^{\circ} \mathrm{C}$, and $550^{\circ} \mathrm{C}$ for $4 \mathrm{~h}$.

\section{Characterization}

X-ray diffraction (XRD) was performed on an X-ray diffractometer (Bruker-AXS D8 Advance, $\mathrm{CuK}_{\alpha}, \lambda=1.54186$ ). The morphology and microstructure of the cathode were observed through an transmission electron microscope (JEOL $2100 \mathrm{~F}$ HRTEM) and scanning electron microscope (JEOL 7600F FESEM). Raman spectra were measured using a Raman system with a laser wavelength of $532 \mathrm{~nm}$ (WITec-CRM200).

\section{LOBs Assembly and Electrochemical Tests}

The homemade Swagelok-type cells which were assembled under pure argon gas $\left(<0.5\right.$ ppm $\mathrm{H}_{2} \mathrm{O}$ and $\left.\mathrm{O}_{2}\right)$ in a glovebox were used for the electrochemical measurements. A free-standing $\mathrm{NiFeRu}$ LDH@GF cathode or a DMO@GF cathode and a Li anode were separated by a Whatman glass fiber separator. The glass fiber separator was first impregnated with $1 \mathrm{M}$ bis(trifluoromethane) sulfonamide (LiTFSI). Tetraethylene glycol dimethyl ether (TEGDME) was used as the solution. The galvanostatic discharge/charge tests were conducted using a Neware battery tester. Electrochemical impedance spectroscopy (EIS) was carried out using CHI660E. The frequency range is from $1 \mathrm{kHz}$ to $1 \mathrm{~Hz}$, and an AC amplitude of $5 \mathrm{mv}$ was applied.

\section{RESULTS AND DISCUSSION}

The crystal structure of NiFeRu-LDH was first researched by XRD. As disclosed in Figure 2A, the diffraction peaks at $11.3^{\circ}$, $22.6^{\circ}$, and $33.9^{\circ}$ are the characteristic (009), (006), and (003) facets of the NiFeRu-LDH, respectively (Chen et al., 2018). The peaks appear at $26.6^{\circ}, 44.7^{\circ}$, and $54.7^{\circ}$ (red triangle symbol) are assigned to the graphite substrate (JCPDS \#89-8487).

The Raman technique was carried out to further identify composition of the as-prepared cathode. The $\mathrm{G}$ band $\left(1,575 \mathrm{~cm}^{-1}\right)$ in the Raman spectrum (Figure $2 \mathbf{B}$ ) is identified for the graphite (Tuinstra and Koenig, 1970). D band $\left(1,348 \mathrm{~cm}^{-1}\right)$ of graphite is not observed, which indicates that 


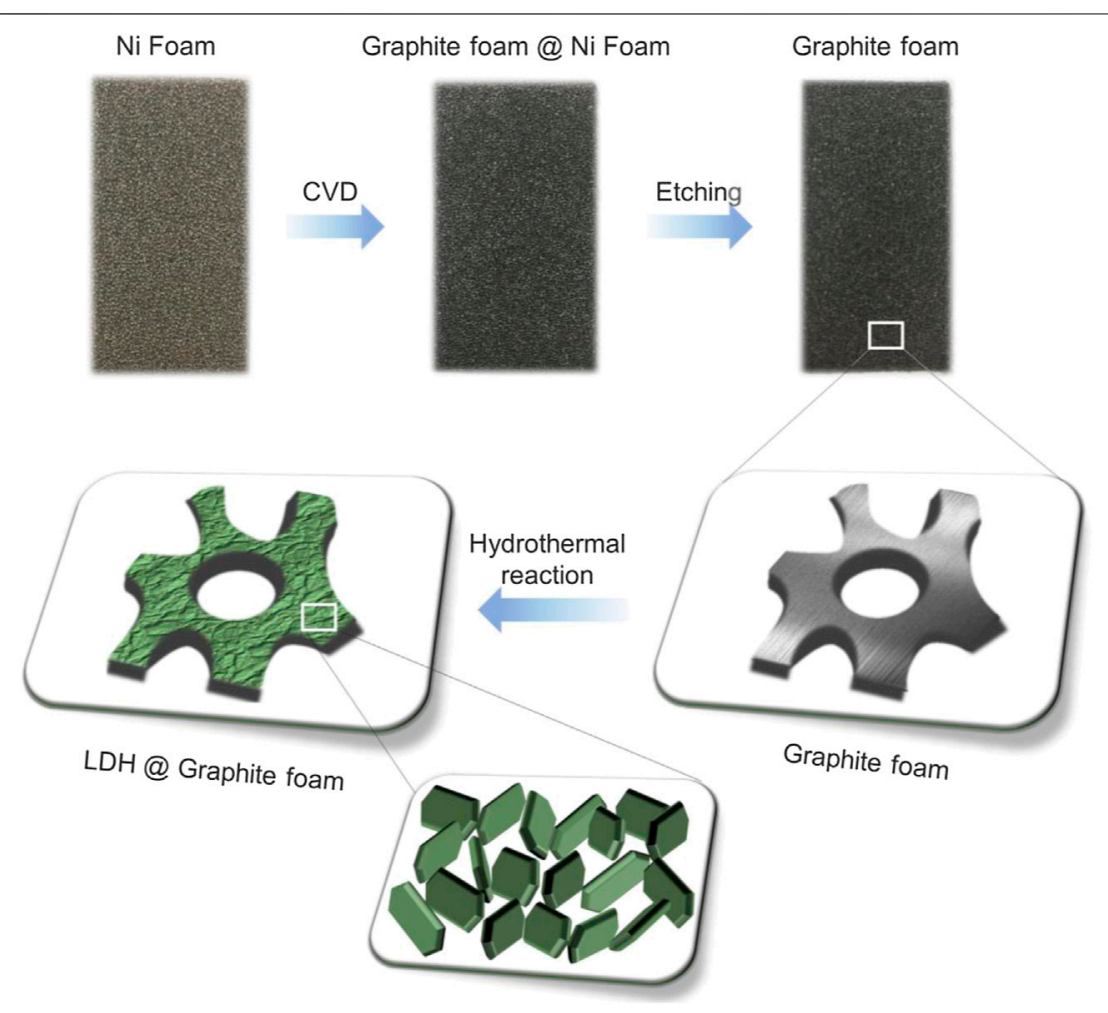

FIGURE 1 | Schematic illustration for the synthesis of NiFeRu-LDH@GF cathode.

the GF is highly ordered (Ferrari et al., 2004). The broad band located at around $547 \mathrm{~cm}^{-1}$ and the faint broad feature at around $458 \mathrm{~cm}^{-1}$ are in accordance with the observation of NiFe-LDH (Lu et al., 2014). The doping of $\mathrm{Ru}$ is responsible for the small shift of Raman peaks for NiFeRu-LDH in comparison with those of $\mathrm{NiFe}-\mathrm{LDH}$.

Field emission scanning electron microscopy (FESEM) was utilized to reveal the morphology of NiFeRu-LDH. NiFeRu-LDH grows uniformly on the surface of GF (Figure 2C). Numerous vertically aligned nanosheets with size of $300-600 \mathrm{~nm}$ and thickness of $20-40 \mathrm{~nm}$ are observed (Figure 2D). This interconnected structure of nanosheet may be helpful in improving the conductivity and providing more active edge sites of NiFeRu-LDH. The transmission electron microscopy (TEM) photograph further uncovers the nanosheet morphology of NiFeRu-LDH (Figure 2E), and the corresponding energy-dispersive X-ray (EDX) elemental mapping discloses the existence of $\mathrm{Ru}$ in the nanosheets (Figure 2F-H). This 3D-structured porous binder-free cathode with a large amount of nanosheets can provide a large reaction interface and abundant highly efficient catalytic active sites for discharging products accommodation.

The electrochemical activity of NiFeRu-LDH@GF is revealed by using the galvanostatic discharge/charge method. Home-made Swagelok-type cells are used to characterize the electrochemical performance. The Li metal is used as anode, and the free-standing NiFeRu-LDH@GF without additional current collectors is the cathode. The cathode and anode are separated by a glass fiber containing electrolyte (details are in the Experimental Section). The first galvanostatic discharging and charging curves of LOBs at various current densities are shown in Figure 3A. The specific discharge capacities of LOBs at $200 \mathrm{~mA} \mathrm{~g}^{-1}, 300 \mathrm{~mA} \mathrm{~g}^{-1}$, and $400 \mathrm{~mA} \mathrm{~g}^{-1}$ are $3,085 \mathrm{mAh} \mathrm{g}^{-1}, \quad 2,155 \mathrm{mAh} \mathrm{g}^{-1}$, and $1,085 \mathrm{mAh} \mathrm{g}^{-1}$, respectively. This result indicates that the specific capacity is sensitive to the current density, which is because of the limited conductivity of discharging products and $\mathrm{O}_{2}$ transport limitation (Viswanathan et al., 2011; Zhu et al., 2013). The mid-capacity potential (defined as the potential at half of the specific capacity) for the discharging process at $200 \mathrm{~mA} \mathrm{~g}^{-1}$ is $2.49 \mathrm{~V}$, which is close to $2.46 \mathrm{~V}$ at $300 \mathrm{~mA} \mathrm{~g}^{-1}$ and $2.43 \mathrm{~V}$ at $400 \mathrm{~mA} \mathrm{~g}^{-1}$. This means the catalytic activity of NiFeRu-LDH@GF for ORR is not the controlling step for the discharging process. However, the mid-capacity potential for the charging process increases from $4.20 \mathrm{~V}$ at $200 \mathrm{~mA} \mathrm{~g}^{-1}$ to $4.32 \mathrm{~V}$ at $400 \mathrm{~mA} \mathrm{~g}^{-1}$. The obviously increased overpotential implies that the catalytic activity of NiFeRu-LDH@GF is not sufficient to OER.

To reveal the cycling performance, the NiFeRu-LDH@GF cathode is tested at a current density of $200 \mathrm{~mA} \mathrm{~g}^{-1}$, and a fixed specific capacity of $500 \mathrm{mAh} \mathrm{g}^{-1}$ is a commonly used parameter in LOBs (Zhou et al., 2017; Zhang et al., 2018). The overpotential gradually increases for the charging process, and the terminal voltage is higher than $4.4 \mathrm{~V}$ after 46 cycles (Figure 3B). Meanwhile, the terminal voltage for the discharging process is about $2.15 \mathrm{~V}$. The performance up to 46 cycles is similar to that of CoNiFe-LDH cathode reported recently (Lu et al., 2020). These 

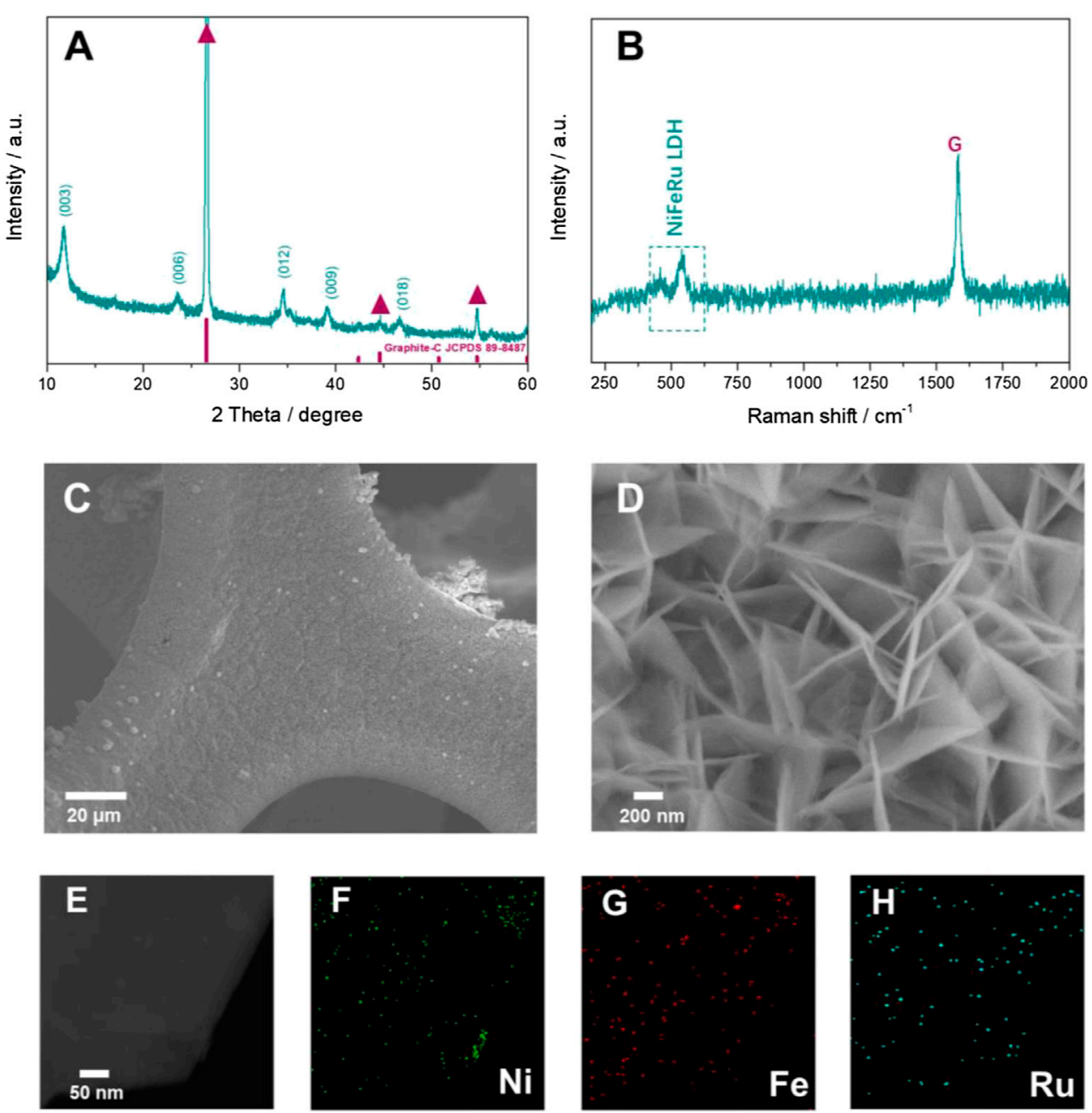

FIGURE 2 | Characterization of the as-fabricated NiFeRu-LDH@GF cathode. Typical (A) XRD, (B) Raman, (C, D) SEM, (E) TEM spectra, and corresponding elemental mapping images of (F) Ni, (G) Fe, and (H) Ru.

results reveal LDHs may not have superior electrochemical properties for LOBs.

To improve the electrochemical performances of LOBs, we further investigate the electrochemical activity of NiFeRu-LDH
DMOs supported on the GF (DMO@GF) obtained by calcining $\mathrm{NiFeRu}-\mathrm{LDH} @ \mathrm{GF}$ at $350^{\circ} \mathrm{C}, 450^{\circ} \mathrm{C}$, and $550^{\circ} \mathrm{C}$, respectively. XRD and Raman spectra reveal the component of DMO@GF in Figure 4. The peaks of graphite substrate still appear at $26.6^{\circ}$,
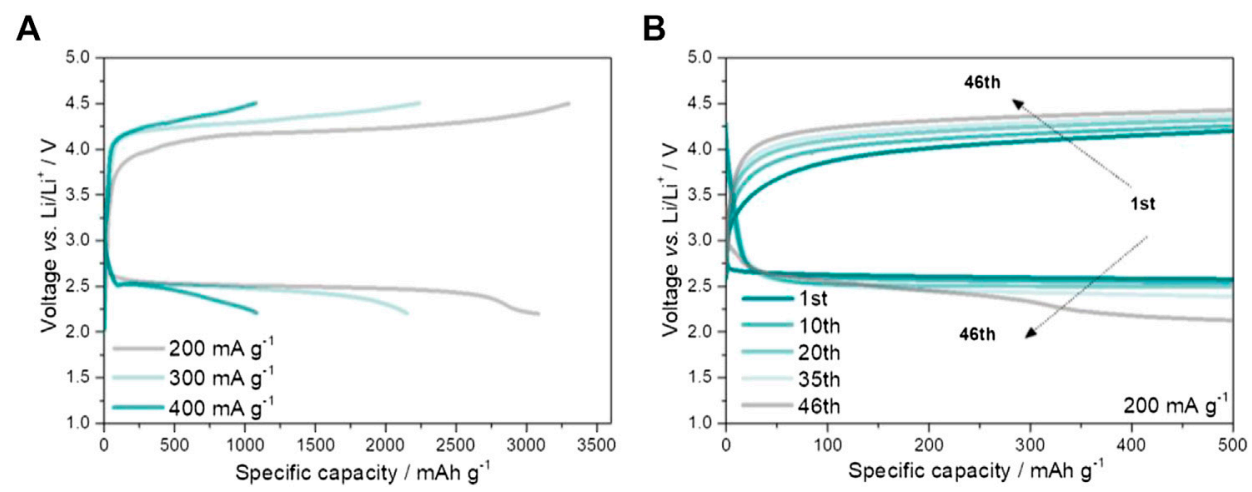

FIGURE 3 | Galvanostatic discharge/charge profiles of NiFeRu-LDH@GF electrodes (A) at different current densities and (B) different cycles. 

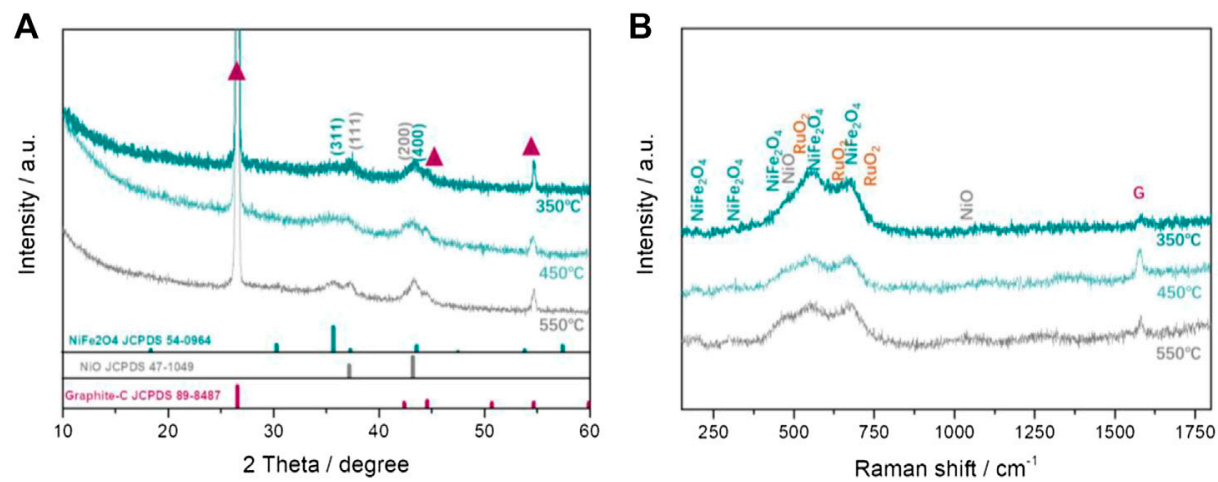

FIGURE 4 | Characterization of the NiFeRu-LDH-derived metal oxides supported on graphite foam. Typical (A) XRD and (B) Raman spectra

$44.7^{\circ}$, and $54.7^{\circ}$ (red triangle symbol, JCPDS \#89-8487), and the peaks of $\mathrm{NiFeRu}-\mathrm{LDH}$ disappear. The diffraction peaks at $35.7^{\circ}$ and $43.4^{\circ}$ are the characteristic (311) and (400) facets of the $\mathrm{NiFe}_{2} \mathrm{O}_{4}$, respectively, and the (111) and (200) facets of $\mathrm{NiO}$ at the peak position of $37.2^{\circ}$ and $43.3^{\circ}$ are also observed in Figure $4 \mathrm{~A}$ (Xue et al., 2020). These results prove that NiFeRu-LDH has changed to metal oxides including $\mathrm{NiFe}_{2} \mathrm{O}_{4}$ and $\mathrm{NiO}$. In addition, the diffraction peak intensity of DMOs increases. In addition, the full width at half maximum (FWHM) decreases when the calcination temperature increases. This means more metal oxides are formed, and their crystal size is larger at higher calcination temperature. The diffraction peaks of $\mathrm{Ru}$ oxides are not detected because of the low $\mathrm{Ru}$ atom ratio in $\mathrm{NiFeRu}-$ LDH.

Raman spectra of DMO@GF further identify the DMOs (Figure 4B). The $\mathrm{G}$ band $\left(1,575 \mathrm{~cm}^{-1}\right)$ of graphite in Raman spectrum still exists, which is consistent with the result of XRD (Figure 4A). The Raman peaks at $188 \mathrm{~cm}^{-1}, 305 \mathrm{~cm}^{-1}, 468 \mathrm{~cm}^{-1}$, and $549 \mathrm{~cm}^{-1}$ are related to the symmetric and antisymmetric bending of oxygen atom in iron-oxygen bond at $\mathrm{FeO}_{6}$ octahedral voids (Kumar et al., 2020). The band at $673 \mathrm{~cm}^{-1}$ is responsible for the symmetric stretching vibrations of oxygen atoms against
$\mathrm{Ni}$ ion in $\mathrm{NiO}_{4}$ tetrahedra. The $\mathrm{NiO}$-related Raman bands at $508 \mathrm{~cm}^{-1}$ and $1,014 \mathrm{~cm}^{-1}$ are also observed in Figure 4B (Qiu et al., 2019). Furthermore, the characteristic peaks of $\mathrm{RuO}_{2}$ at $528 \mathrm{~cm}^{-1}, 646 \mathrm{~cm}^{-1}$, and $716 \mathrm{~cm}^{-1}$ are included in the broad bands between $450 \mathrm{~cm}^{-1}$ and $750 \mathrm{~cm}^{-1}$ (Huang and Pollak, 1982). These results predict a conclusion that NiFeRu-LDH has transformed to metal oxides on GF.

Galvanostatic discharge/charge method was further utilized to investigate the electrochemical performances of DMO@GF cathode by calcining NiFeRu-LDH@GF at $350^{\circ} \mathrm{C}, 450^{\circ} \mathrm{C}$ and $550^{\circ} \mathrm{C}$ (denoted as 350-DMO@GF, 450-DMO@GF and 550DMO@GF). The specific discharge capacities of 350-DMO@ GF, 450-DMO@GF and 550-DMO@GF electrodes are 2,718 $\mathrm{mAh} \mathrm{g}^{-1}, 3,700 \mathrm{mAh} \mathrm{g}^{-1}$, and 2,555 $\mathrm{mAh} \mathrm{g}^{-1}$, respectively (Figure 5A). Obviously, only the 450-DMO@GF exhibits higher specific discharge capacity than that of NiFeRu-LDH@GF (Figure 3A). Meanwhile, the mid-capacity potential for the discharging process of $450-\mathrm{DMO} @ \mathrm{GF}$ is $2.55 \mathrm{~V}$ which is close to 2.56 V of 350-DMO@GF and 2.50 V of 550-DMO@GF. This means the discharging over-potential of DMO@GF, especially 450-DMO@GF, is smaller than that of NiFeRu-LDH@GF $(2.49 \mathrm{~V})$. More importantly, the mid-capacity potential of
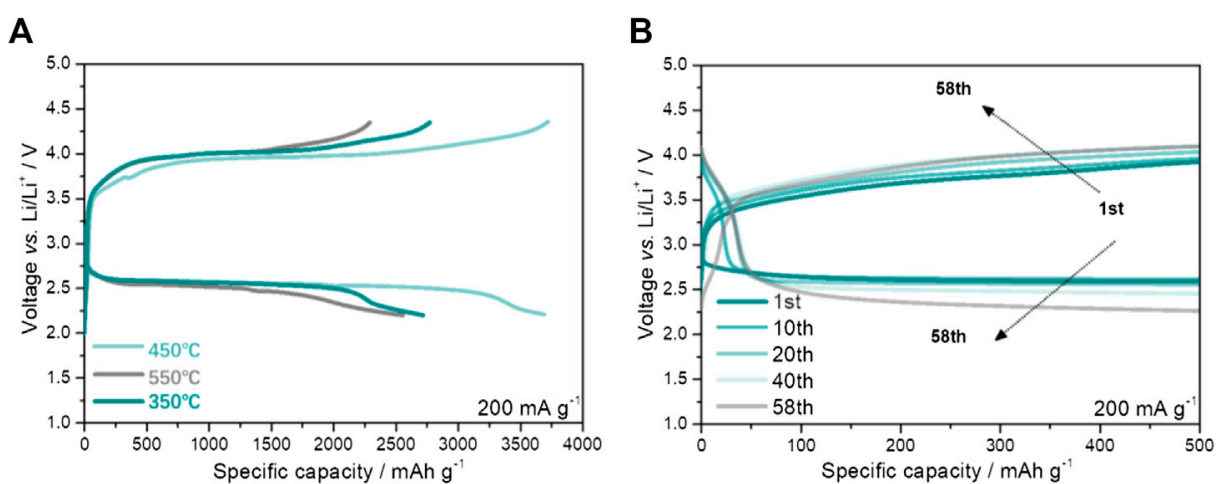

FIGURE 5 | (A) Galvanostatic discharge/charge profiles of DMO@GF electrodes and (B) the cycling performance of 450-DMO@GF cathode. The current density is $200 \mathrm{~mA} \mathrm{~g}^{-1}$. 

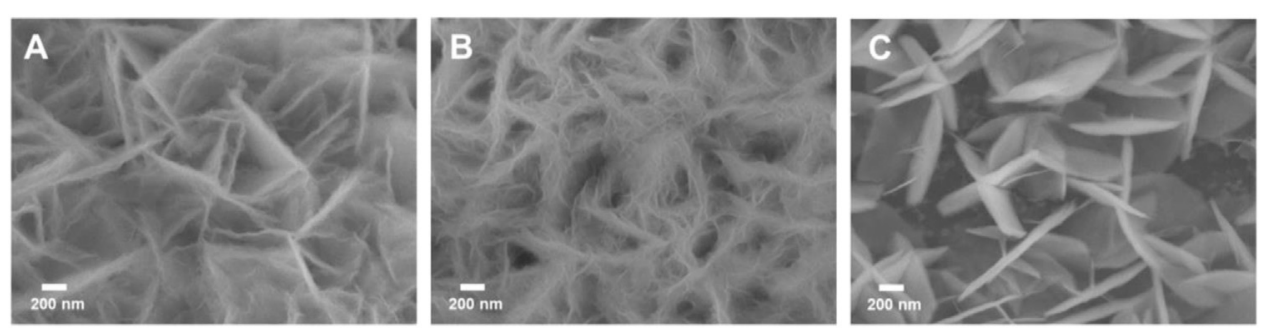

FIGURE 6 | SEM spectra of the (A) 350-DMO@GF, (B) 450-DMO@GF, and (C) 550-DMO@GF.

DMO@GF for the charging process (4.02 V for 350-DMO@GF, $3.97 \mathrm{~V}$ for 450-DMO@GF and 4.01 V for 550-DMO@GF) is much lower than that of NiFeRu-LDH@GF (4.20 V). The cycling properties of 450-DMO@GF cathode are further researched since it has highest specific discharging capacity and smallest charging over-potential (Figure 5B). The cycle life of 58 is realized for 450-DMO@GF cathode at a current density of $200 \mathrm{mAg}^{-1}$ and a fixed specific capacity of $500 \mathrm{mAh} \mathrm{g}^{-1}$. The terminal voltage for charging and discharging process is $4.08 \mathrm{~V}$ and $2.25 \mathrm{~V}$. These cycling performances of 450-DMO@GF are better than those of NiFeRu-LDH@GF (Figure 3B). These results imply that the NiFeRu-LDH DMOs have higher catalytic activity for ORR and OER process in comparison with $\mathrm{NiFeRu}-\mathrm{LDH}$. It has been reported that metal oxides such as $\mathrm{NiCo}_{2} \mathrm{O}_{4}, \mathrm{NiO}$ and $\mathrm{RuO}_{2}$ have better electrochemical performances than those of layered-double-hydroxides (Chang et al., 2017), which is consistent with our results.

To reveal the differences of electrochemical performance for NiFeRu-LDH DMOs, the morphology and structure of DMO@ $\mathrm{GF}$ are analyzed by SEM. At a low temperature of $350^{\circ} \mathrm{C}$, the vertically aligned nanosheets of $\mathrm{NiFeRu}-\mathrm{LDH}$ partially changed

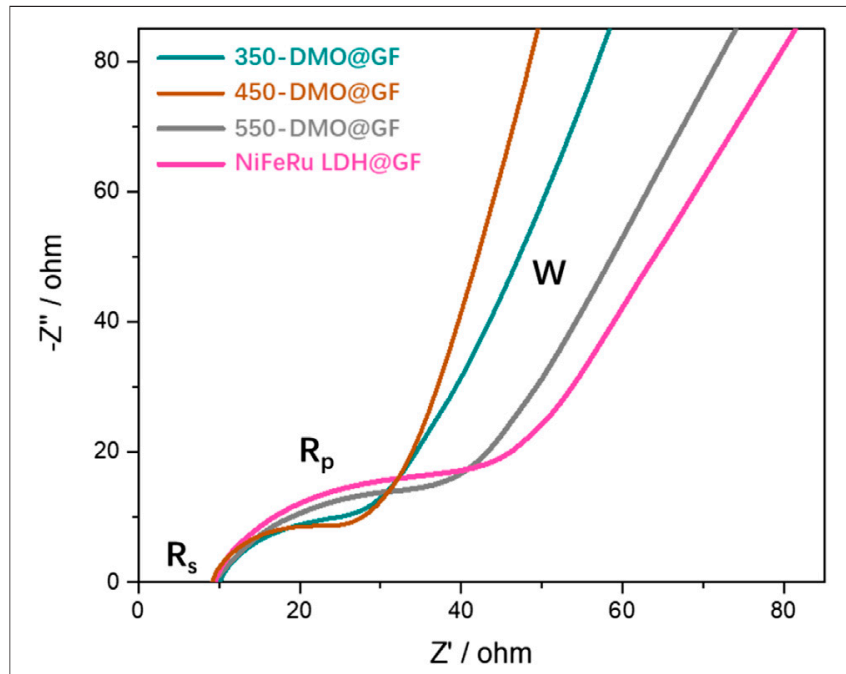

FIGURE 7 | Nyquist plots of DMO@GF and LDH@GF. to floccule-like products because of the phase transformation from NiFeRu-LDH to DMOs (Figure 6A). Then, all the nanosheets of NiFeRu-LDH change to floccule-like DMOs that are cross-connected after calcining $450^{\circ} \mathrm{C}$ (Figure 6B). The floccule-like DMOs further grow to thick nanosheets since the crystal grains grow up accompanying the temperature rising, and no floccule-like products are observed at $550^{\circ} \mathrm{C}$ (Figure 6C). Obviously, the high specific surface combined with the crossconnected structure of the floccule-like DMOs is beneficial to improve the electrocatalytic activity and meanwhile to lower the overpotential. Therefore, the 450-DMO@GF electrode has the best charge-discharge performance among three DMO@GF electrodes.

EIS is further introduced to research the mechanism of differences in kinetic characteristic among DMO@GF and LDH@GF (Figure 7). The impedance spectra of LOBs are interpreted and proposed by Laoire. The equivalent circuit is Rs $\left(C\left(R_{p} W\right)\right.$, where Rs is the electronic resistance from the cathode, the current collector, and electrolyte resistance, $\mathrm{C}$ is the capacitive contribution of the cathode and anode, $R_{p}$ is the charge transfer resistance of the two electrodes, and $\mathrm{W}$ is the linear Warburg element that is attributed to the diffusion of the $\mathrm{O}_{2}$ and $\mathrm{Li}^{+}$species to the electrode (Laoire et al., 2011). Obviously, the charge transfer resistance $R_{p}$ of three DMO@GF electrodes is smaller than that of LDH@GF, which implies that DMO@GF electrodes have higher catalytic activity in LOBs. In addition, the charge transfer resistance of the 450-DMO@GF electrode is smallest among the three DMO@GF electrodes, which is responsible for its outstanding electrochemical performance. These results are consistent with the discharge/charge characteristic of DMO@GF and LDH@GF (Figures 3, 5).

\section{CONCLUSION}

In summary, we present an integrated binder-free cathode for LOBs based on Ru-doped NiFe layered double hydroxide grown on a GF (NiFeRu LDH@GF) through hydrothermal reaction. The vertically aligned $\mathrm{NiFeRu} \mathrm{LDH}$ nanosheets combined with the ultralight and conductive GF substrate provide a specific capacity of $3,085 \mathrm{mAh} \mathrm{g}^{-1}$ at $200 \mathrm{~mA} \mathrm{~g}^{-1}$ and a cycle life of 46 . Furthermore, we also investigate the NiFeRu LDH DMOs supported on a GF (DMO@GF) by calcining NiFeRu LDH@ $\mathrm{GF}$ at $350^{\circ} \mathrm{C}, 450^{\circ} \mathrm{C}$, and $550^{\circ} \mathrm{C}$. The $450^{\circ} \mathrm{C}$-obtained DMO@GF 
(450-DMO@GF) shows the best electrochemical performances among the three DMO@GFs. The specific capacity of 450DMO@GF is $3,700 \mathrm{mAh} \mathrm{g}^{-1}$, and its cycle life is 58 . SEM reveals that the floccule-like 450-DMO@GF has a high specific surface combined with a cross-connected structure. EIS further reveals that the charge transfer resistance of the 450-DMO@GF electrode is smallest. Our results provide a new kind of integrated binder-free cathode to achieving LOBs with high performance.

\section{DATA AVAILABILITY STATEMENT}

The original contributions presented in the study are included in the article/supplementary materials, further inquiries can be directed to the corresponding author/s.

\section{REFERENCES}

Abraham, K., and Jiang, Z. (1996). A polymer electrolyte-based rechargeable lithium/oxygen battery. J. Electrochem. Soc. 143, 1-5. doi:10.1149/1.1836378

Bruce, P. G., Freunberger, S. A., Hardwick, L. J., and Tarascon, J.-M. (2012). Li-O2 and Li-S batteries with high energy storage. Nat. Mater. 11, 19-29. doi:10.1038/ nmat3191

Cai, Z., Bu, X., Wang, P., Ho, J. C., Yang, J., and Wang, X. (2019). Recent advances in layered double hydroxide electrocatalysts for the oxygen evolution reaction. J. Mater. Chem. A 7, 5069-5089. doi:10.1039/c8ta11273h

Chang, Z., Xu, J., and Zhang, X. (2017). Recent progress in electrocatalyst for LiO2Batteries. Adv. Energy Mater. 7, 1700875. doi:10.1002/aenm.201700875

Chao, D., Xia, X., Liu, J., Fan, Z., Ng, C. F., Lin, J., et al. (2014). A V2O5/conductivepolymer core/shell nanobelt array on three-dimensional graphite foam: a highrate, ultrastable, and freestanding cathode for lithium-ion batteries. Adv. Mater. 26, 5794-5800. doi:10.1002/adma.201400719

Chen, G., Wang, T., Zhang, J., Liu, P., Sun, H., Zhuang, X., et al. (2018). Accelerated hydrogen evolution kinetics on NiFe-layered double hydroxide electrocatalysts by tailoring water dissociation active sites. Adv. Mater. 30, 1706279. doi:10. 1002/adma.201706279

Ferrari, A., Robertson, J., Reich, S., and Thomsen, C. (2004). Raman spectroscopy of graphite. Phil. Trans. Roy. Soc. Lond. 362, 2271-2288. doi:10.1098/rsta.2004.1452

Freunberger, S. A., Chen, Y., Peng, Z., Griffin, J. M., Hardwick, L. J., Bardé, F., et al. (2011). Reactions in the rechargeable lithium-O2Battery with alkyl carbonate electrolytes. J. Am. Chem. Soc. 133, 8040-8047. doi:10.1021/ja2021747

Gong, M., Li, Y., Wang, H., Liang, Y., Wu, J. Z., Zhou, J., et al. (2013). An advanced Ni-Fe layered double hydroxide electrocatalyst for water oxidation. J. Am. Chem. Soc. 135, 8452-8455. doi:10.1021/ja4027715

Gu, Z., Atherton, J. J., and Xu, Z. P. (2015). Hierarchical layered double hydroxide nanocomposites: structure, synthesis and applications. Chem. Commun. 51, 3024-3036. doi:10.1039/c4cc07715f

Huang, Y. S., and Pollak, F. H. (1982). Raman investigation of rutile RuO2. Solid State Commun. 43, 921-924. doi:10.1016/0038-1098(82)90930-9

Jiang, Z.-L., Sun, H., Shi, W.-K., Cheng, J.-Y., Hu, J.-Y., Guo, H.-L., et al. (2019). P-doped hive-like carbon derived from pinecone biomass as efficient catalyst for Li-O2 battery. ACS Sustain. Chem. Eng. 7, 14161-14169. doi:10.1021/acssuschemeng.9b02790

Kumar, A., Singh, A. K., Tomar, M., Gupta, V., Kumar, P., and Singh, K. (2020). Electromagnetic interference shielding performance of lightweight NiFe2O4/ rGO nanocomposite in X- band frequency range. Ceram. Int. 46, 15473-15481. doi:10.1016/j.ceramint.2020.03.092

Laoire, C. O., Mukerjee, S., Plichta, E. J., Hendrickson, M. A., and Abraham, K. M. (2011). Rechargeable lithium/TEGDME-LiPF[sub 6/O[sub 2] battery. J. Electrochem. Soc. 158, A302. doi:10.1149/1.3531981

Liu, T., Leskes, M., Yu, W., Moore, A. J., Zhou, L., Bayley, P. M., et al. (2015). Cycling Li-O2 batteries via $\mathrm{LiOH}$ formation and decomposition. Science 350, 530-533. doi:10.1126/science.aac7730

\section{AUTHOR CONTRIBUTIONS}

All authors extensively discussed the results, reviewed the manuscript, and approved the final version of the manuscript to be published.

\section{FUNDING}

This work was financially supported by the National Natural Science Foundation of China (No. 22075115), the Natural Science Foundation of Jiangsu Province (BK20171,169), the Natural Science Foundation of the Jiangsu Higher Education Institutions of China (19KJA430020, 18KJA430015), the Jiangsu Qing Lan Project $(2020,2018)$ and the innovation and entrepreneurship training program for college students (xcx2020135).

Lu, J., Jung Lee, Y., Luo, X., Chun Lau, K., Asadi, M., Wang, H.-H., et al. (2016). A lithium-oxygen battery based on lithium superoxide. Nature 529, 377-382. doi:10.1038/nature16484

Lu, X., Sakai, N., Tang, D., Li, X., Taniguchi, T., Ma, R., et al. (2020). CoNiFe layered double hydroxide/ $\mathrm{RuO} 2.1$ nanosheet superlattice as carbon-free electrocatalysts for water splitting and Li-O2 batteries. ACS Appl. Mater. Interfaces 12, 33083-33093. doi:10.1021/acsami.0c07656

Lu, Z., Xu, W., Zhu, W., Yang, Q., Lei, X., Liu, J., et al. (2014). Three-dimensional NiFe layered double hydroxide film for high-efficiency oxygen evolution reaction. Chem. Commun. 50, 6479-6482. doi:10.1039/c4cc01625d

Lyu, Z., Zhou, Y., Dai, W., Cui, X., Lai, M., Wang, L., et al. (2017). Recent advances in understanding of the mechanism and control of $\mathrm{Li} 2 \mathrm{O} 2$ formation in aprotic Li-O2batteries. Chem. Soc. Rev. 46, 6046-6072. doi:10.1039/c7cs00255f

Ottakam Thotiyl, M. M., Freunberger, S. A., Peng, Z., and Bruce, P. G. (2013). The carbon electrode in nonaqueous Li-O2 cells. J. Am. Chem. Soc. 135, 494-500. doi:10.1021/ja310258x

Qin, L., Lv, W., Wei, W., Kang, F., Zhai, D., and Yang, Q.-H. (2019). Oxygenenriched carbon nanotubes as a bifunctional catalyst promote the oxygen reduction/evolution reactions in Li-O2 batteries. Carbon 141, 561-567. doi:10.1016/j.carbon.2018.10.025

Qiu, Z., Ma, Y., and Edvinsson, T. (2019). In operando Raman investigation of Fe doping influence on catalytic $\mathrm{NiO}$ intermediates for enhanced overall water splitting. Nanomater. Energy 66, 104118. doi:10.1016/j.nanoen.2019.104118

Ribeiro, L. N. M., Alcântara, A. C. S., Darder, M., Aranda, P., Araújo-Moreira, F. M., and Ruiz-Hitzky, E. (2014). Pectin-coated chitosan-LDH bionanocomposite beads as potential systems for colon-targeted drug delivery. Int. J. Pharm. 463, 1-9. doi:10.1016/j.ijpharm.2013.12.035

Seh, Z. W., Kibsgaard, J., Dickens, C. F., Chorkendorff, I., Nørskov, J. K., and Jaramillo, T. F. (2017). Combining theory and experiment in electrocatalysis: insights into materials design. Science 355, eead4998. doi:10.1126/science. aad4998

Song, M., Tan, H., Li, X., Tok, A. I. Y., Liang, P., Chao, D., et al. (2020). Atomiclayer-deposited amorphous MoS 2 for durable and flexible Li-O 2 batteries. Small Methods 4, 1900274. doi:10.1002/smtd.201900274

Sun, B., Huang, X., Chen, S., Zhao, Y., Zhang, J., Munroe, P., et al. (2014). Hierarchical macroporous/mesoporous NiCo2O4nanosheets as cathode catalysts for rechargeable Li-O2batteries. J. Mater. Chem. A 2, 12053-12059. doi:10.1039/c4ta01888e

Sun, C., Shi, X., Zhang, Y., Liang, J., Qu, J., and Lai, C. (2020). Ti3C2Tx MXene interface layer driving ultra-stable lithium-iodine batteries with both high iodine content and mass loading. ACS Nano 14, 1176-1184. doi:10.1021/ acsnano.9b09541

Tong, S., Zheng, M., Lu, Y., Lin, Z., Li, J., Zhang, X., et al. (2015). Mesoporous NiO with a single-crystalline structure utilized as a noble metal-free catalyst for non-aqueous LiO2 batteries. J. Mater. Chem. A 3, 16177-16182. doi:10.1039/c5ta03685b

Tuinstra, F., and Koenig, J. L. (1970). Raman spectrum of graphite. J. Chem. Phys. 53, 1126-1130. doi:10.1063/1.1674108 
Viswanathan, V., Thygesen, K. S., Hummelshøj, J. S., Norskov, J. K., Girishkumar, G., Mccloskey, B. D., et al. (2011). Electrical conductivity in Li2O2 and its role in determining capacity limitations in non-aqueous Li-O2 batteries. J. Chem. Phys. 135, 214704. doi:10.1063/1.3663385

Xue, P., Sun, C., Li, H., Liang, J., and Lai, C. (2019). Superlithiophilic amorphous $\mathrm{SiO} 2$-TiO 2 distributed into porous carbon skeleton enabling uniform lithium deposition for stable lithium metal batteries. Adv. Sci. 6, 1900943. doi:10.1002/ advs.201900943

Xue, Z., Li, L., Cao, L., Zheng, W., Yang, W., and Yu, X. (2020). A simple method to fabricate NiFe2O4/NiO@Fe2O3 core-shelled nanocubes based on Prussian blue analogues for lithium ion battery. J. Alloys Compd. 825, 153966. doi:10.1016/j. jallcom.2020.153966

Yuan, M., Zhang, S., Lin, L., Sun, Z., Yang, H., Li, H., et al. (2019). Manganese carbodiimide nanoparticles modified with $\mathrm{N}$-doping carbon: a bifunctional cathode electrocatalyst for aprotic Li-O2 battery. ACS Sustain. Chem. Eng. 7, 17464-17473. doi:10.1021/acssuschemeng.9b04674

Zhang, T., Zou, B., Bi, X., Li, M., Wen, J., Huo, F., et al. (2019). Selective growth of a discontinuous subnanometer Pd film on carbon defects for Li-O2 batteries. ACS Energy Lett. 4, 2782-2786. doi:10.1021/acsenergylett.9b02202

Zhang, X., Wang, C., Chen, Y.-N., Wang, X.-G., Xie, Z., and Zhou, Z. (2018). Binder-free NiFe $2 \mathrm{O} 4 / \mathrm{C}$ nanofibers as air cathodes for Li-O 2 batteries. J. Power Sources 377, 136-141. doi:10.1016/j.jpowsour.2017.12.002

Zhao, Y., Li, B., Wang, Q., Gao, W., Wang, C. J., Wei, M., et al. (2014). NiTiLayered double hydroxides nanosheets as efficient photocatalysts for oxygen evolution from water using visible light. Chem. Sci. 5, 951-958. doi:10.1039/ c3sc52546e
Zhou, Y., Lyu, Z., Wang, L., Dong, W., Dai, W., Cui, X., et al. (2017). Co3O4 functionalized porous carbon nanotube oxygen-cathodes to promote $\mathrm{Li} 2 \mathrm{O} 2$ surface growth for improved cycling stability of Li-O2 batteries. J. Mater. Chem. A 5, 25501-25508. doi:10.1039/c7ta09932k

Zhu, D., Zhang, L., Song, M., Wang, X., Mi, R., Liu, H., et al. (2013). Intermittent operation of the aprotic Li-O2 battery: the mass recovery process upon discharge interval. J. Solid State Electrochem. 17, 2539-2544. doi:10.1007/ s10008-013-2116-1

Conflict of Interest: The authors declare that the research was conducted in the absence of any commercial or financial relationships that could be construed as a potential conflict of interest.

Publisher's Note: All claims expressed in this article are solely those of the authors and do not necessarily represent those of their affiliated organizations or those of the publisher, the editors, and the reviewers. Any product that may be evaluated in this article or claim that may be made by its manufacturer is not guaranteed or endorsed by the publisher.

Copyright (c) 2020 Song, Tan, Tian, Li, Xu, Shi, Sun, Zhuang and Du.. This is an open-access article distributed under the terms of the Creative Commons Attribution License (CC BY). The use, distribution or reproduction in other forums is permitted, provided the original author(s) and the copyright owner(s) are credited and that the original publication in this journal is cited, in accordance with accepted academic practice. No use, distribution or reproduction is permitted which does not comply with these terms. 